\title{
Estafilococos: morfologia das colônias, produção de coagulase e enterotoxina a, em amostras isoladas de leite cru refrigerado
}

\section{Staphylococci: colonies morphological caracteristics, coagulase and EEA production colected from cooled raw milk samples}

\author{
Elsa Helena Walter de Santana ${ }^{1}$; Vanerli Beloti2 ${ }^{*}$; Tereza Cristina R. M. de Oliveira ${ }^{3}$; \\ Luciane B. de Moraes ${ }^{4}$; Ronaldo Tamanini ${ }^{5}$; Wladimir P. Silva ${ }^{6}$
}

\begin{abstract}
Resumo
Os relatos de intoxicação estafilocócica, principalmente por $S$. aureus, são frequentemente associados à ingestão de $100 \mathrm{ng}$ de enterotoxina/g ou $\mathrm{mL}$ de alimento. A produção de enterotoxina pelos estafilococos está associada fortemente à produção de coagulase. Neste trabalho foram avaliadas amostras de leite de 51 propriedades leiteiras em Londrina (RS) e 50 em Pelotas. Todas as 101 amostras apresentaram contagens de estafilococos coagulase positivos (ECP). Das 552 colônias avaliadas, 256 foram coagulase positivas e destas cerca de 60\% eram típicas no àgar Baird Parker e, em média, 60\% do total de 296 estafilococos coagulase negativos (ECN) eram colônias atípicas. Quanto à capacidade enterotoxigênica, testou-se 109 colônias ECP, sendo 5,5\% (6) positivas e $18 \mathrm{ECN}$, sendo 1 (5,5\%) positiva. Assim, a freqüência de ECN produtores de EEA $(5,5 \%)$ foi semelhante a dos ECP. Conclui-se que há extensa contaminação do leite cru por ECP, sendo grande parte (40\%) das colônias atípicas produtoras de coagulase.

Palavras-chave: Leite, estafilococos, toxinfecção, coagulase
\end{abstract}

\begin{abstract}
The stories of food poisoning from staphylococci, mainly by S. aureus, are frequently associates to the ingestion of food with $100 \mathrm{ng}$ of enterotoxin/g or $\mathrm{mL}$. The production of enterotoxin using staphylococci is strongly associated with the production of coagulase. In this paper, milk samples of 51 milk properties in Londrina (RS) and 50 in Pelotas had been evaluated. All the 101 samples had presented counts of coagulase positive staphylococci (CPS). From 552 colonies studied, 256 were CPS where $60 \%$ of the colonies were typical in Baird Parker agar and, from 296 coagulase negative staphylococcus (CNS), in mean, $60 \%$ were atypical colonies. Due to the enterotoxigenic capacity, were tested $109 \mathrm{CPS}$, being 5,5\% (6) positive and 18 CNS where $1(5,5 \%)$ were positive. The frequency of CPS EEA $(5,5 \%)$ producer was similar of the CNS. There is a wide milk contamination with CPS, where, a big part (40\%) of the atypical colonies is coagulase producers.
\end{abstract}

Key words: Milk, staphylococci, toxic infection, coagulase

\footnotetext{
1 Pós Graduação em Ciência Animal (Departamento de Ciências Agrárias)- Universidade Estadual de Londrina. E-mail: elsawalter@uol.com.br

2 Professora do Departamento de Medicina Veterinária Preventiva, atua na área inspeção de Produtos de Origem Animal, Universidade Estadual de Londrina.

3 Professora do departamento de Tecnologia de Alimentos e Medicamentos, Universidade Estadual de Londrina.

4 Pós Graduação em Ciência Animal (Departamento de Ciências Agrárias)- Universidade Estadual de Londrina.

5 Pós Graduação em Ciência Animal (Departamento de Ciências Agrárias)- Universidade Estadual de Londrina.

6 Departamento de Ciência e Tecnologia Agroindustrial, Universidade Federal de Pelotas.

* Autor para correspondência.
} 


\section{Introdução}

As intoxicações estafilocócicas ocorrem devido a ingestão de toxina pré formada no alimento, e são frequentemente associadas à ingestão de $100 \mathrm{ng}$ de enterotoxina (EE) e contagens entre $10^{5}-10^{6} \mathrm{UFC}$ de estafilococos/ g ou mL de alimento (WONG; BERGDOLL, 2002; LANCETTE; TATINI, 1992; PARK; AKTAR; RAYMAN, 1992)

O homem e os animais são os principais reservatórios de $S$. aureus, sendo a cavidade nasal do homem seu principal habitat (WONG; BERGDOLL, 2002; FRANCO; LANDGRAF, 1996). O S. aureus é também um dos principais agentes da mastite bovina, contaminando o leite na sua obtenção (SILVA et al., 2000).

Os principais sintomas da intoxicação estafilocócica são náuseas, vômito, cãibras abdominais e diarréia. O período de incubação varia de 30 minutos a 8 horas, sendo em média entre 2 e 4 horas (LE LOIR; BARON; GAUTIR, 2003; WONG; BERGDOLL, 2002; DINGES; ORWIN; SCLIEVERT, 2000; SU; WONG, 1997) e a recuperação completa entre 1 e 3 dias (SU; WONG, 1997).

Alguns fatores de virulência dos estafilococos são associados à sua capacidade enterotoxigênica, entre eles a produção de coagulase (PEREIRA; PEREIRA, 2005; PEREIRA et al., 2000).

Quanto aos estafilococos coagulase negativos (ECN), estes são associados a uma série de outras infecções em homens e animais. Para Orden et al. (1992), ECN podem produzir quantidades menores de EE quando comparados com $S$. aureus, mas não devem ser excluídos quando presentes em alimentos envolvidos em surtos de intoxicações alimentares.

O método de eleição para enumeração dos estafilococos em alimentos é o método de contagem em placas utilizando o àgar Baird - Parker. Este àgar combina o telurito de potássio $(0,01 \%)$, glicina $(1,2 \%)$ e cloreto de lítio $(0,5 \%)$ como agentes seletivos e, a redução do telurito de potássio e a hidrólise da gema de ovo como características diferenciais das colônias típicas e atípicas de estafilococos. Desta forma, as colônias típicas são aquelas negras, brilhantes, delimitadas e com dois halos, sendo associada estas características a capacidade do microrganismo em produzir a enzima coagulase, e consequentemente ser um potencial produtor de enterotoxina (SILVA; JUNQUEIRA; SILVEIRA, 1997).

Atualmente são descritas em torno de dezoito enterotoxinas estafilocócicas sorologicamente distintas: EEA, EEB, EEC1, EEC2, EEC3, EED e EEG a EER e EEU (JORGENSEN et al., 2005).

Sabe-se que o Brasil conta com poucos dados epidemiológicos a respeito das doenças veiculadas por alimentos. No entanto, estima-se que as intoxicações estafilocócicas sejam muito comuns no país, sendo a maioria dos casos não investigados ou não notificados.

Assim, neste estudo pretendeu-se determinar em isolados de amostras de leite cru coletadas nas regiões de Londrina(PR) e Pelotas(RS) a contagem de estafilococos, a característica morfológica das culturas isoladas em àgar Baird - Parker, e sua capacidade de produção de enterotoxina $\mathrm{A}$.

\section{Material e Métodos}

\section{Propriedades}

Para a realização da pesquisa foram selecionadas 101 propriedades leiteiras, sendo 51 em Londrina(PR) e 50 em Pelotas (RS). Estas regiões foram selecionadas, pois representavam duas regiões do país onde há produção leiteira, com condições climáticas distintas e que ofereceram apoio laboratorial para o desenvolvimento da pesquisa. As propriedades foram selecionadas segundo a representatividade quanto às práticas de manejo e instalações predominantes em cada região.

As amostras de leite "in natura" refrigerado foram coletas a partir dos tanques de expansão ou imersão, utilizando-se frascos estéreis, transportados sob 
refrigeração imediatamente aos laboratórios onde as pesquisas estavam sendo realizadas. Em Londrina, as amostras foram analisadas na Universidade Estadual de Londrina, no Laboratório de Inspeção de Produtos de Origem Animal, e na cidade de Pelotas as amostras foram analisadas na Universidade Federal de Pelotas, no Departamento de Ciência e Tecnologia Agroindustrial.

A partir das amostras de leite coletadas, procedeuse a enumeração de Staphylococcus spp., a determinação da produção de coagulase e de cepas enterotoxigêncicas.

\section{Análises Microbiológicas}

Isolamento, enumeração e identificação de Staphylococcus spp.

As análises foram realizadas conforme os Métodos de Análise Microbiológica para Alimentos - Brasil (1993), utilizando o agar Baird - Parker (Merck, Darmstadt, Alemanha) para semeadura em superfície. Realizou-se diluições decimais seriadas e foram selecionadas para contagem, preferencialmente, as placas de cada diluição que continham entre 10 e 150 colônias, coletando-se para prova da coagulase 5 colônias típicas e 5 atípicas. Quando o número de colônias da menor diluição foi inferior a 5, todas as colônias foram coletadas para a prova da coagulase.

O resultado da enumeração de Staphylococcus spp. (UFC/mL) foi corrigido de acordo com a diluição e quantidade de inóculo utilizados, considerando-se o número de colônias típicas e atípicas contadas e a porcentagem de colônias coagulase positivas confirmadas (SILVA; JUNQUEIRA; SILVEIRA, 1997).

\section{Prova da coagulase}

As colônias selecionadas foram repicadas para o caldo BHI (Infusão de Cérebro e Coração) (Difco, Detroit, EUA) e após 24 hs a $35-37^{\circ} \mathrm{C}$ realizou-se a prova da coagulase, conforme AOAC (1995).

\section{Provas bioquímicas complementares}

A prova da catalase foi utilizada para diferenciação entre os gêneros Staphylococccus e Streptococcus. Para diferenciar estafilococos coagulase negativos e Micrococccus utilizou-se a prova da sensibilidade a lisostafina (FOOD AND DRUG ADMINISTRATION, 1995). As espécies S.aureus, S. intermedius e S. hycus foram diferenciadas avaliando a capacidade de utilização anaeróbica e aeróbica do manitol e utilização aeróbica da maltose (FOOD AND DRUG ADMINISTRATION, 1995; PHILLIPS JÚNIOR; KLOOS, 1981).

Avaliação da capacidade de produção de Eea pelos estafilococos

Para determinação da capacidade de produzir enterotoxina A, testaram-se 109 culturas de estafilococos coagulase positivos (ECP) e 18 culturas de estafilococos coagulase negativos (ECN) isoladas das 101 amostras de leite cru refrigerados coletadas nas regiões de Londrina e Pelotas. As amostras estudadas foram estocadas em àgar nutriente (Difco, Detroti, EUA) a temperatura média de $8^{\circ} \mathrm{C}$ e recuperadas em caldo BHI (Difco, Detroti, EUA) a $35-37^{\circ} \mathrm{C} / 24$ horas para realização da análise. As amostras de ECP selecionadas foram aquelas identificadas bioquimicamente como $S$. aureus, $S$. intermedius e $S$. hycus, tanto na prova da maltose quanto na do manitol. A seleção dos ECN foi realizada de forma aleatória, de acordo com a disponibilidade de análises.

\section{Produção de enterotoxinas}

Para verificar a produção de enterotoxina pelos estafilococos, utilizou-se Cellophane-over-Agar (JARWIS; LAWRENCE, 1970). Sobre placas de Petri (60 X12 mm) com ágar BHI (Difco, Detroti, EUA) recobertas por papel celofane estéril, semeouse $0,1 \mathrm{~mL}$ de uma suspensão de estafilococos em caldo BHI (Difco, Detroti, EUA), contendo 1\% de extrato de levedura, e incubou-se por 24 horas a 35 - 
$37^{\circ} \mathrm{C}$. A cultura obtida foi removida utilizando-se 1,5 $\mathrm{mL}$ de uma solução estéril de $\mathrm{NaH}_{2} \mathrm{PO}_{4} 0,01 \mathrm{M}$ e centrifugada por 3 minutos (Microcentrífuga Iwaki, 10.000 RPM). O sobrenadante foi recolhido e utilizado para o teste de imunodifusão.

\section{Toxina, linhagens padrões e anti-soro específico para EEA}

Anti-soros policlonais para EEA foram produzidos no Laboratório de Ciência de Alimentos, Departamento de Tecnologia de Alimentos e Medicamentos do Centro de Ciências Agrárias da Universidade Estadual de Londrina (OLIVEIRA; HIROOKA, 1999). A toxina EEA pura e linhagens padrões (FRI 722 e FRI A100) de S. aureus produtores de EEA foram cedidas gentilmente pelo Dr. Merlin S. Bergdoll do Food Research Institute, Wisconsin, USA.

\section{Imunodifusão (Optimum Sensitivity Plate)}

Para visualização da capacidade de produzir EEA das 109 culturas selecionadas, utilizou-se método de imunodifusão-OSP (Optimum Sensitivity Plate) (ROBBINS; GOULD; BERGDOLI, 1974). O meio de imunodifusão foi preparado com $8,5 \mathrm{~g}$ de $\mathrm{NaCl}$, $5,0 \mathrm{~mL}$ de solução mertiolate a $2 \%$ e $12,0 \mathrm{~g}$ de àgar de alta pureza dissolvidos em $1000 \mathrm{~mL}$ de tampão Tris $0,05 \mathrm{M}$, ph 7,4. A mistura foi aquecida até completa dissolução do àgar e filtrada quente através de papel de filtro.

Placas de Petri (50x12mm) foram revestidas com ágar-ágar 0,2\% (Biotec, Suffolk, Inglaterra), secas em estufa e adicionadas de $4 \mathrm{~mL}$ de meio para imunodifusão fundido. Após solidificação e descanso por 24 horas sob refrigeração, foram feitos seis orifícios, seguindo o diâmetro e a distância descrita por Robbins, Gould e Bergdoli (1974). No orifício central da placa, foram colocadas $75^{1 / 41}$ de antisoro padrão e nos orifícios menores, superiores e inferiores, $50^{1 / 41}$ da respectiva toxina padrão. Nos orifícios laterais foram adicionados $75^{1 / 41}$ do sobrenadante das culturas a serem testadas. As placas foram incubadas em câmara úmida a $35-37^{\circ}$ C / 24h, e a leitura realizada adicionando-se solução de ácido fosfórico $0,1 \mathrm{M}$ para melhor visualização das linhas de precipitação.

\section{Resultados e Discussão}

Todas as 101 propriedades analisadas neste experimento, apresentaram contagens de estafilococos coagulase positivos (ECP). Destas, 19 $(18,8 \%)$ apresentaram contagem de ECP acima de $10^{5} \mathrm{UFC} / \mathrm{mL}$ no leite cru refrigerado. Na região de Londrina, $13(25,5 \%)$ amostras apresentaram contagens entre $10^{5}$ e $10^{6} \mathrm{UFC} / \mathrm{mL}$ e duas acima de $10^{6}(3,9 \%)$. Em Pelotas foram $04(8,0 \%)$ as amostras com contagens entre $10^{5}$ e $10^{6} \mathrm{UFC} / \mathrm{mL}$.

Das amostras colhidas nas 101 propriedades selecionou-se 552 colônias de estafilococos isolada do Àgar Baird - Parker e testadas quanto à produção de coagulase, sendo 321 oriundas da região de Londrina e 231 de Pelotas.

Para correlação entre morfologia da colônia e capacidade de produção de coagulase, obtiveramse, a partir de 51 amostras de leite de diferentes propriedades leiteiras de Londrina, 321 colônias, sendo $115(35,8 \%)$ consideradas típicas (negras, brilhantes, bem delimitadas e com dois halos) de $S$. aureus e $206(64,2 \%)$ atípicas. Das 115 colônias típicas, $74(64,34 \%)$ foram capazes de produzir coagulase, e das 206 atípicas, $86(41,74 \%)$ produziram a enzima. Assim, obteve-se 160 colônias produtoras de coagulase sendo 74 (46,25\%) com morfologia típica de $S$. aureus e $86(53,75 \%)$ de colônias atípicas. Dos ECN isolados, $41(24,46 \%)$ apresentaram colônias típicas e 120 (74,53\%) colônias atípicas (Tabela 1). Do total de colônias analisadas, praticamente $50 \%$ das colônias isoladas na região de Londrina produziram coagulase.

Em Pelotas das 50 amostras de leite analisadas, isolou-se 231 culturas de estafilococo, sendo 108 $(46,8 \%)$ culturas típicas e $123(53,2 \%)$ atípicas de $S$. 
aureus. Os estafilococos produtores de coagulase com característica típica das culturas totalizaram 61 $(64,89 \%)$ amostras e aquelas atípicas 35 (35,1\%), números bastante semelhantes aos encontrados em Londrina. Aqueles estafilococos coagulase negativos com culturas típicas foram $47(34,81 \%)$ e com característica atípica $88(65,18 \%)$ (Tabela 1$)$.

Tabela 1. Morfologia e capacidade de produção de coagulase de 552 colônias de estafilococos isolados no àgar BairdParker, a partir de amostras de leite cru refrigerado nas regiões de Pelotas (RS) e Londrina (PR).

\begin{tabular}{ccccc}
\hline Região & $\begin{array}{c}\text { Característica } \\
\text { morfológica }\end{array}$ & Colônias de ECP & Colônias de ECN & Total \\
\hline Londrina & Típicas* & $74(46,25 \%)$ & $41(24,46 \%)$ & 115 \\
& Atípicas & $86(53,75 \%)$ & $120(74,53 \%)$ & 206 \\
& Subtotal & $160(100,0 \%)$ & $161(100,0 \%)$ & 321 \\
Pelotas & Típicas* & $61(64,89 \%)$ & $47(34,81 \%)$ & 108 \\
& Atípicas & $35(35,1 \%)$ & $88(64,18 \%)$ & 123 \\
& SubTotal & $94(100,0 \%)$ & $135(100,0 \%)$ & 231 \\
\multirow{5}{*}{ Total } & Típicas* & $135(60,53 \%)$ & $88(39,46 \%)$ & 223 \\
& Atípicas & $121(36,77 \%)$ & $208(63,22 \%)$ & 329 \\
& Total & 256 & 296 & 552 \\
\hline
\end{tabular}

*Colônias negras, brilhantes, bem delimitadas e com dois halos no àgar Baird - Parker.

Desta forma, pode-se observar que nas duas regiões houve predomínio de culturas atípicas de estafilococos, independentemente da capacidade de produção da enzima coagulase. No entanto, das colônias coagulase positivas coletadas na região de Pelotas 64,89\% (61) foram caracterizadas como típicas de $S$. aureus, enquanto na região de Londrina apenas $46,25 \%$ das colônias coagulase positivas eram típicas. Assim, neste estudo, boa parte das colônias atípicas de estafilococos $(36,8 \%)$ produziu coagulase (Tabela 1).

Silva et al. (2000) relataram que de 274 cepas de $S$. aureus isoladas de leite mastítico, mão de ordenhador e equipamentos de ordenha, $108(39,4 \%)$ eram colônias atípicas, sendo $102(94,4 \%)$ isoladas de amostras de leite. A maioria das colônias atípicas (106 das 108) avaliadas pelos autores foi positiva na prova da coagulase. Sendo assim, torna-se importante considerar aquelas colônias atípicas de estafilococos no àgar Baird - Parker como cepas potencialmente associadas a surtos de intoxicação estafilocócica, já que existe a correlação entre a capacidade do microrganismo de produzir a coagulase e sintetizar a enterotoxina.

Para determinação da capacidade enterotoxigênica (EEA) das culturas de estafilococos isoladas das amostras de leite (Tabela 2), através da técnica de imunodifusão (OSP), foram testadas 109 colônias coagulase positivas, sendo 94 culturas S.aureus, 11 de $S$. hycus e 04 de $S$. intermedius e 18 coagulase negativos. Deste total, apenas $6(5,5 \%)$ das culturas ECP testadas tinham a capacidade de produzir pelo menos $100 \mathrm{ng}$ de EEA por $\mathrm{mL}$ de sobrenadante, todas típicas de $S$. aureus, podendo ainda haver a presença de cepas pauciprodutoras de EEA não identificadas pelo teste utilizado. Quanto aos estafilococos coagulase negativos testados para a capacidade de produzirem EEA, uma das 18 culturas foi positiva $(5,55 \%)$, mesma porcentagem encontrada entre os ECP (Tabela 2).

A freqüência de estafilococos produtores de EEA neste estudo foi semelhante à encontrada por Cardoso, Carmo e Silva. (2000) que, utilizando à mesma técnica de OSP, avaliaram 127 amostras de 
estafilococos isolados de leite de animais com mastite e encontraram, em torno de 3\% (4) com capacidade de produção de EEA. Outros autores, utilizando-se de técnicas como a aglutinação em látex e microslide para pesquisa de EEA em amostras de leite encontraram culturas de estafilococos produtoras de pouca quantidade de EEA e culturas não produtoras isoladamente desta toxina (JORGENSEN et al., 2005; CENCI-GOGA et al., 2003; OMBUI; ARIMI; KAYIHURA, 1992; HILL, 1983)
A produção de enterotoxinas por espécies ECN já foi relatada. O primeiro relato ocorreu em 1959 no Japão, associado ao consumo de leite contaminado. O segundo correu em 1969 nos Estados Unidos através da ingestão de carne assada e mais recentemente em 2002 no Brasil, resultante do consumo de leite cru contaminado com $S$. epidermidis produtor de EEC (PEREIRA; PEREIRA, 2005; CARMO, 2002).

Tabela 2. Avaliação da capacidade de produção de (EEA) por culturas de estafilococos coagulase positivos e negativos, isoladas de amostras de leite cru refrigerado de propriedades leiteiras da região de Londrina (PR) e Pelotas (RS), entre os meses de abril e dezembro de 2003, utilizando a técnica de imunodifusão (OSP).

\begin{tabular}{|c|c|c|c|c|}
\hline Total de colônias & Espécie & $\begin{array}{l}\text { Origem das } \\
\text { amostras }\end{array}$ & $\begin{array}{c}\text { Colônias OSP } \\
\text { positivas }\end{array}$ & $\begin{array}{l}\text { Contagem de estafilococos das } \\
\text { amostras de leite positivas no OSP }\end{array}$ \\
\hline 94 & S. aureus* & $\begin{array}{l}\text { Pelotas (43) } \\
\text { Londrina (51) }\end{array}$ & $\begin{array}{l}\text { Pelotas (02) } \\
\text { Londrina (04) }\end{array}$ & $10^{3}-10^{5} \mathrm{UFC} / \mathrm{mL}$ \\
\hline 11 & S. hycus* & $\begin{array}{l}\text { Pelotas }(05) \\
\text { Londrina (06) }\end{array}$ & 0 & ----- \\
\hline 04 & $\begin{array}{c}\text { S. } \\
\text { intermedius* }\end{array}$ & Londrina (04) & 0 & ------ \\
\hline Subtotal & -- & $\begin{array}{l}\text { Pelotas (48) } \\
\text { Londrina (61) }\end{array}$ & --- & --- \\
\hline 18 & $\begin{array}{c}\text { Staphylococcu } \\
\text { S spp. } \\
\text { Coagulase } \\
\text { negativa** }\end{array}$ & $\begin{array}{c}\text { Pelotas (12) } \\
\text { Londrina (06) }\end{array}$ & Pelotas (01) & $10^{4} \mathrm{UFC} / \mathrm{mL}$ \\
\hline Total & -- & $\begin{array}{l}\text { Pelotas }(60) \\
\text { Londrina (67) }\end{array}$ & --- & --- \\
\hline
\end{tabular}

* Culturas de ECP testadas: representaram 40 amostras de leite

** Culturas de ECN testadas: representaram 15 amostras de leite

De acordo com Zoli, Negrete e Oliveira (2002) os surtos de intoxicação alimentar estão relacionados à contaminação de alimentos por $S$. aureus enterotoxigênicos. Para Santos (2003), a importância dos ECN em diversas patologias de seres humanos e animais é indiscutível, mas sua participação em surtos de intoxicações alimentares não tem sido verificada. Pereira, Carmo e Pereira (2001), ao avaliarem o comportamento de ECN pauciprodutoras, inocularam estas linhagens em leite UHT e presunto cozido e encontraram contagens de estafilococos variando entre $10^{5}$ e $10^{9} \mathrm{UFC} / \mathrm{mL}$, não sendo possível a detecção da EE nos alimentos em questão. O ideal seria que, tanto para o controle da qualidade dos alimentos como para elucidação de surtos de intoxicação alimentar, se procedesse também a detecção da enterotoxina no alimento. No entanto, o custo destas análises inviabiliza o procedimento.

O fato de até hoje os ECN serem pouco relacionados às intoxicações, não quer dizer que isso não possa vir a acontecer, uma vez que são vários os estudos relatando sua capacidade de produzir enterotoxina, principalmente "in vitro". Seria recomendável o estudo de capacidade 
enterotoxigênica em um número maior de ECN isolados de leite cru, bem como inoculações em leite para verificar a produção da toxina no alimento.

Neste estudo, embora houvesse disparidade entre o número de ECN e ECP analisados, pode-se dizer que a freqüência de ECN produtores de EEA (5,55\%) (1 de 18 culturas isoladas) foi semelhante ao dos produtores de coagulase (5,5\%) (6 de 109 culturas isoladas). Assim se o alimento proporcionar condições para o crescimento e produção de toxina pela população estafilocócica, há possibilidade de ocorrer toxinfecção envolvendo também os ECN.

\section{Conclusões}

Todas as amostras de leite cru avaliadas apresentaram ECP. No entanto, a maioria dos isolados não eram enterotoxigênicos ou não expressavam esta característica.

Nas duas regiões avaliadas houve predomínio de culturas atípicas de estafilococos, independentemente da capacidade de produção da enzima coagulase.

Boa parte das colônias atípicas de estafilococos produz coagualse.

A freqüência de ECN produtores de EEA foi semelhante ao dos produtores de coagulase.

Tanto ECN como ECP apresentaram, "in vitro", capacidade de produzirem enterotoxina, indicando possibilidade de intoxicação estafilocócica por ambos, se o alimento em questão oferecer condições para o desenvolvimento destes microrganismos e produção de toxinas.

\section{Referências}

AOAC. International Official Methods of Analysis. 16.ed. Gaithersburg: AOAC International, 1995.

BRASIL. Ministério da Agricultura, do Abastecimento e da Reforma Agrária. Métodos de análise microbiológica para alimentos:1991 e 1992. 2.ed. Brasília: o Ministério, 1993.
CARDOSO, H. F. T.; CARMO, L. S.; SILVA, N. Detecção da toxina-1 da síndrome do choque tóxico em amostras de S. aureus isoladas de mastite bovina. Arquivo Brasileiro de Medicina Veterinária e Zootecnia, Belo Horizonte, v.52, n.1, p.7-10, 2000.

CARMO, L. S. Revista Minas Faz Ciência, n.11, jun/ag, 2002. Disponível em: <http://revista.fapemig.br.htm>. Acesso em: 09 maio 2005.

CENCI-GOGA, B. T.; KARAMA, M.; ROSSITO, P. V.; MORGANTE, R. A.; CULLOR, J. S. Enterotoxin production by $S$. aureus isolated from mastitic cows. Journal of Food Protection, Des Moines, v.66, n.9, p.1693-1696, 2003.

DINGES, M. M.; ORWIN, P. M.; SCHLIEVERT, P. M. Exotoxins of $S$. aureus. Clinical Microbiology Reviews, Washington, v.13, n.1, p.16-34, 2000.

FOOD AND DRUG ADMINISTRATION. Bacteriological analytical manual. 8 ed. Gaithersburg: AOAC International, 1995.

FRANCO, B. D. G. M.; LANDGRAF, M. Microbiologia dos Alimentos. São Paulo: Atheneu, 1996.

HILL, B. M. Enterotoxin productinh S. aureus isolated from milk and dairy products. New Zealand Journal of Dairy Science and Technology, Hamilton, v.18, n.1, p.5962, 1983.

JARWIS, A. W.; LAWRENCE, R. C. Production of high titers of enterotoxins for the routine testing of staphylococci. Applied Microbiology, Washington, v.19, n.4, p.698-699, 1970.

JORGENSEN,H.J.; MORK,T.; HOGASEN, H. R.; RORVIK, L. M. Enterotoxigenic S. aureus in bulk milk in Norway. Journal of Applied Microbiology, Oxford, v.99, n.1, p.158166, 2005.

LANCETTE, G. A; TATINI, S. R. Staphylococcus aureus. In: VANDRZANT, C. Compendium of Methods for the Microbiological Examination of Foods. 3.ed. Washington: American Public Heath Association, 1992.

LE LOIR, Y.; BARON, F.; GAUTIR, M. Staphylococcus aureus and food poisoning. Genetic and Molecular Research, Ribeirão Preto, v.2, n.1, p.63-76, 2003.

OLIVEIRA, T. C. R. M.; HIROOKA, E. Y. Low cost production and purification of polyclonal antibodies to staphylococcal enterotoxin A. Revista de Microbiologia, São Paulo, v.30, p.120-124, 1999.

OMBUI, J. N.; ARIMI, S. M.; KAYIHURA, M. Raw milk as a source of enterotoxigenic $S$. aureus and enterotoxins in consumer milk. East African Medical Journal, Nairobi, v.69, n.3, 1992. 
ORDEN, J. A.; GOYACHE, J.; HERNANDEZ, J.; DOMENECH, A.; SUAREZ, G.; GOMEZ-LUCIA, E. Production of staphylococcal enterotoxins and TSST-1 by coagulase negative staphylococci isolate from ruminant mastitis. Journal of Veterinary Medicine: Séries $B$, Berlin, v.39, p.144-148, 1992.

PARK, C. E.; AKTAR, M.; RAYMAN, K. Nonespecific reactions of a commercial enzyme-linked immunoabsorbent assay kit (Tecra) for detection of staphylococcal enterotoxinas in foods. Applied and Environmental Microbiology, Washington, v.58, n.8, p.2509-2512, 1992.

PEREIRA, K. S.; PEREIRA, J. L. Estafilococos coagulase negativa: potenciais patógenos em alimentos. Revista Higiene Alimentar, São Paulo, v.19, n.129, p.32-34, 2005

PEREIRA, M. A.; PEREIRA, J. L.; SERRANO, A. M.; BERDOLL,M. S. Estafilococos: até onde sua importância em alimentos? Revista Higiene Alimentar, São Paulo, v.14, n.68, p.32-39, 2000.

PEREIRA, M. L.; CARMO, L. S.; PEREIRA, J. L. Comportamento de estafilococos coagulase negativos pauciprodutores de enterotoxinas em alimentos experimentalmente inoculados. Ciência e Tecnologia de Alimentos, Campinas, v.21, n.2, p.171-175, 2001.

PHILLIPS, JÚNIOR., W. E.; KLOOS, W. E. Identification of coagulase-positive $S$. intermedius and $S$. hycus sub sp. hycus isolate from veterinary clinical specimens. Journal of Clinical Microbiology, Washington, v.14, n.6, p.671673, 1981.
ROBBINS, R. N.; GOULD, S.; BERGDOLL, M. S. Detecting the enterotoxigenity of Staphylococcus aureus strains. Applied Microbiology, Washington, v.28, p.946-950, 1974.

SANTOS, A. Estudo comparativo entre a PCR e técnicas imunológicas (ELISA, RPLA e OSP) na enterotoxigenicidade de isolados de estafilococos coagulse negativa. 2003. Dissertação (Mestrado em Ciência dos Alimentos) - Universidade Estadual de Londrina, Londrina.

SILVA, N.; JUNQUEIRA, V. C. A.; SILVEIRA, N. F. A. Manual de métodos de análise microbiológica de alimentos. São Paulo: Livraria Varela, 1997.

SILVA, W. P.; DESTRO, M. T.; LANDGRAF, M.; FRANCO, B. D. G. M. Biochemical characteristics of typical and atypical Staphylococcus aureus in mastitic milk and environmental samples of Brazilian dairy farms. Brazilian Journal of Microbiology, São Paulo, v.31, n.2, p.103-106, 2000 .

SU, Y. C.; WONG, A. C. L. Current perspectives on detection of staphylococcal enterotoxins. Journal of Food Protection, Des Moines, v.60, n.2, p.195-202, 1997.

WONG, A. C. L.; BERGDOLL, M. S. Staphylococcal food poisoning. 2.ed. London: Elsevier, 2002.

ZOLI, J. A.; NEGRETE, I. R. A.; OLIVEIRA, T. C. R. M. Avaliação da contaminação por $S$. aureus e Salmonella spp. , de maionese de batata comercializada em Londrina, PR. Revista Higiene Alimentar, São Paulo, v.16, n.95, p.6270, abr. 2002. 